03

\title{
Наносекундная ионизация области обтекания прямоугольного уступа высокоскоростным потоком
}

\author{
() И.А. Знаменская, Д.И. Татаренкова, Т.А. Кули-заде \\ Московский государственный университет им. М.В. Ломоносова, Москва, Россия \\ E-mail: znamen@phys.msu.ru
}

Поступило в Редакцию 9 сентября 2019г.

В окончательной редакции 9 сентября 2019г.

Принято к публикации 18 сентября 2019г.

\begin{abstract}
Описано явление перераспределения плазмы и тока импульсного объемного разряда на основе самолокализации при инициировании в нестационарном течении в ударной трубе сечением $48 \times 24 \mathrm{~mm}$. Показано, что на участке газодинамического канала с уступом в форме параллелепипеда в потоке за фронтом ударной волны с числами Маха 2.8-3.5 в течение $2800 \mu$ s реализуются короткоживущие плазменные каналы в зонах отрыва около уступа.
\end{abstract}

Ключевые слова: ударная волна, плазма импульсного разряда, область отрыва потока, электрический ток.

DOI: 10.21883/PJTF.2020.01.48854.18027

Электрические разряды являются достаточно эффективным средством для активного управления газодинамическими потоками различных конфигураций, включая сверхзвуковые течения [1,2]. Импульсный разряд с наносекундным фронтом нарастания тока сопровождается быстрым ростом (за время менее $1 \mu \mathrm{s}$ ) температуры и давления в зоне разряда, что обусловлено высоким значением вложенной в газ энергии в ограниченной области. Плазменная зона генерирует ударную (взрывную) волну на своей границе [3]. Ее конфигурация и интенсивность зависят от локализации разряда, структуры газового потока и распределения плотности в зоне локализации разряда. Поверхностные разряды могут быть использованы для управления пограничным слоем [4,5], включая зоны отрыва пограничного слоя на обтекаемой поверхности. Особое внимание уделяется управлению отрывом при обтекании уступов [6,7]. Импульсный объемный разряд может существенно изменить высокоскоростное течение в газодинамическом канале $[8,9]$. При этом эффект самолокализации импульсного разряда в неоднородном потоке позволяет прогнозировать и контролировать импульсное и импульсно-периодическое воздействие на поток.

В настоящей работе проведено экспериментальное исследование перераспределения плазмы импульсного объемного разряда в спутном потоке за движущейся в канале ударной трубы ударной волной в поле течения, формирующемся после дифракции волны на прямоугольном уступе (прямая и обратная ступеньки). В литературе имеется большое количество данных о дифракции ударной волны на прямых и обратных уступах и их обтекании $[10,11]$. Визуализация течений осуществлялась преимущественно теневыми, интерферометрическими методами [12]. Метод визуализации импульсным объемным разрядом позволяет зарегистрировать зоны пониженной плотности на основе интегральной регистрации свечения разряда в потоке [13]. При этом зоны повышенного свечения являются источниками возмущений и ударных волн, влияющих на поток после окончания тока разряда.

Цель работы - определение зон локализации энергии сильноточного объемного разряда при различных условиях отрывного обтекания препятствия. Эксперименты проводились на стенде УТРО-3, представляющем собой диафрагменную ударную трубу со специальной разрядной камерой $[3,8,9]$. Импульсный объемный разряд с предыонизацией от плазменных листов (электродов) инициировался в канале прямоугольного сечения размером $24 \times 48 \mathrm{~mm}$ в различные моменты движения плоской ударной волны и потока за ней. Исходная плоская ударная волна проходила через препятствие в виде параллелепипеда, размещенного на нижней стенке камеры ударной трубы (рис. 1). Ионизация потока импульсным объемным разрядом с предыонизацией ультрафиолетовым излучением от плазменных листов (электродов) [3] происходила на участке газодинамического канала длиной $10 \mathrm{~cm}$; прямоугольный уступ (параллелепипед размером $48 \times 6.2 \times 1.9 \mathrm{~mm})$ был закреплен на расстоянии $1.5 \mathrm{~cm}$ от передней кромки плазменного электрода (ниже по потоку). Длительность тока разряда, измеренная по осциллограммам, полученным с низкоиндуктивного

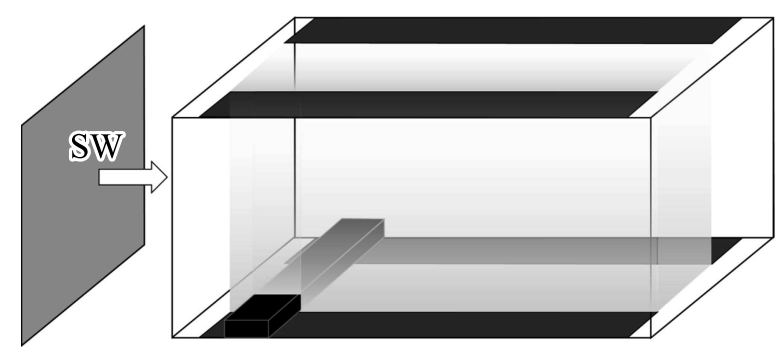

Рис. 1. Схема разрядной секции с ударной волной. 

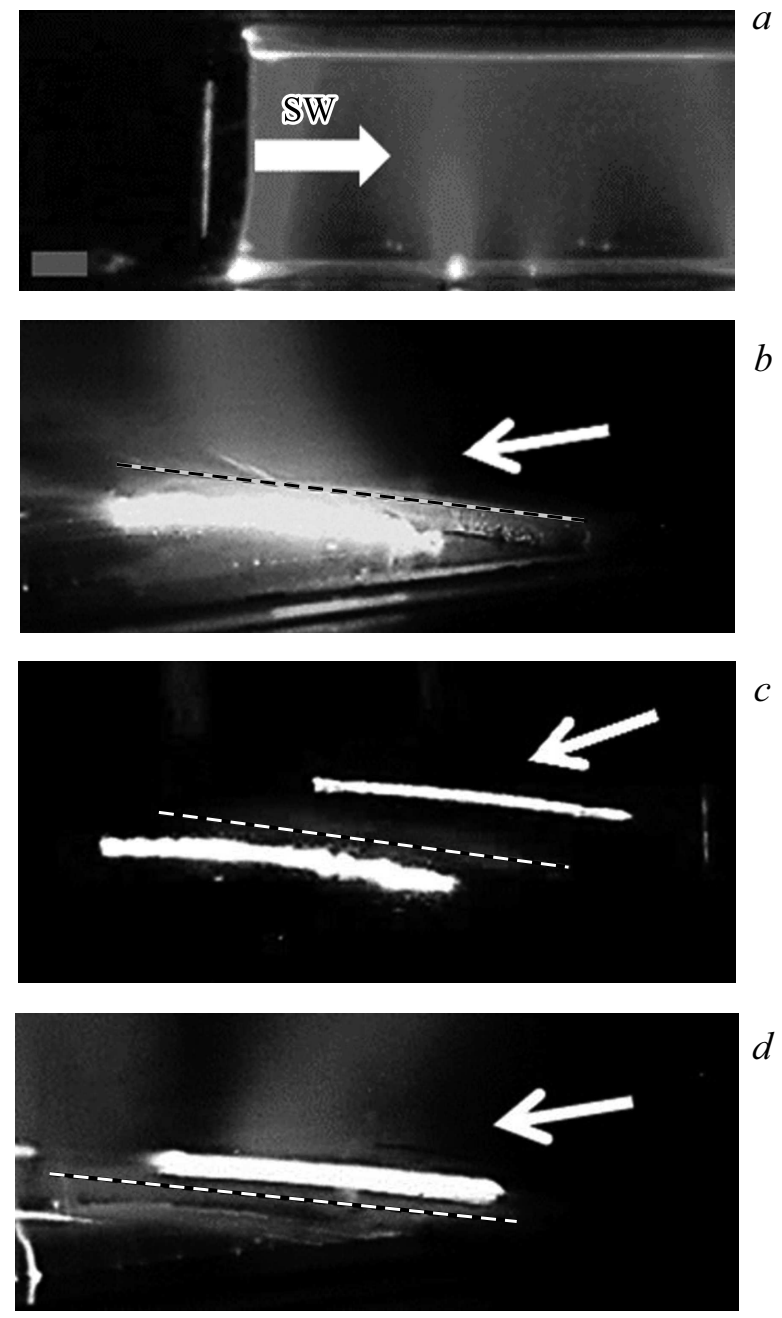

Рис. 2. $a-$ разряд при движении ударной волны после дифракции (поток слева направо); $b-d-$ эффект самолокализации плазмы до $600 \mu \mathrm{s}$, при $600-1200 \mu \mathrm{s}$, после $1200 \mu \mathrm{s}$ соответственно (поток справа налево).

шунта, составляла 150-300 ns, а длительность свечения разряда - до $1-2 \mu \mathrm{s}$ [3]. Исследовалась ионизация потока воздуха с плоской ударной волны с числом Маха $\mathrm{M}=2.8-3.5$ и потока за ней с числом Маха 1.3-1.5. Визуализация потока осуществлялась через боковые стенки рабочей камеры, которые представляли собой кварцевые окна длиной $17 \mathrm{~cm}$. Интегральные изображения свечения разряда в поле течения регистрировались с двух сторон испытательной (разрядной) камеры. Зарегистрированы и исследованы мгновенные изображения свечения плазмы, возникающие при инициировании объемного разряда в потоке в моменты времени от $t=0$ (касание уступа) до $t=2800 \mu \mathrm{s}$.

При дифракции ударной волны на препятствии последовательно происходят отражение разрыва от прямого уступа с установлением обтекания с головной волной [11], огибание обратного уступа, установление обтекания с ударной волной перед уступом, скачками уплот- нения, зонами отрыва (пониженной плотности [10]). Свечение разряда, в частности, визуализирует зоны локализации энергии в областях мгновенного разрежения. Интенсивность свечения коррелирует с распределением плотности в потоке за счет того, что локальный коэффициент ионизации является нелинейной функцией $E / N$ (здесь $E-$ мгновенное электрическое поле, $N-$ концентрация молекул).

Было зарегистрировано явление линейной самолокализации плазмы импульсного объемного разряда вдоль направляющей прямоугольного уступа в потоке за ударной волной и зафиксирован эффект перемещения канала самолокализации плазмы по мере эволюции параметров обтекания препятствия спутным потоком. На рис. 2, a представлено изображение свечения плазмы при движении ударной волны (обозначена стрелкой) после прохождения препятствия при ионизации канала импульсным объемным разрядом с предыонизацией от плазменных листов. Свечение разряда зафиксировано в областях низкой плотности: перед фронтом ударной волны и в зоне отрыва за препятствием на нижней стенке канала.

Зафиксировано три основных режима линейной локализации разряда на участке потока вблизи препятствия (рис. 2, $b-d$, на снимках штриховой линией отмечена верхняя грань уступа с подветренной стороны; стрелками указано направление потока вдоль центра канала). Обнаружено, что через несколько микросекунд после прохода ударной волны через препятствие происходит локализация поперечного плазменного канала

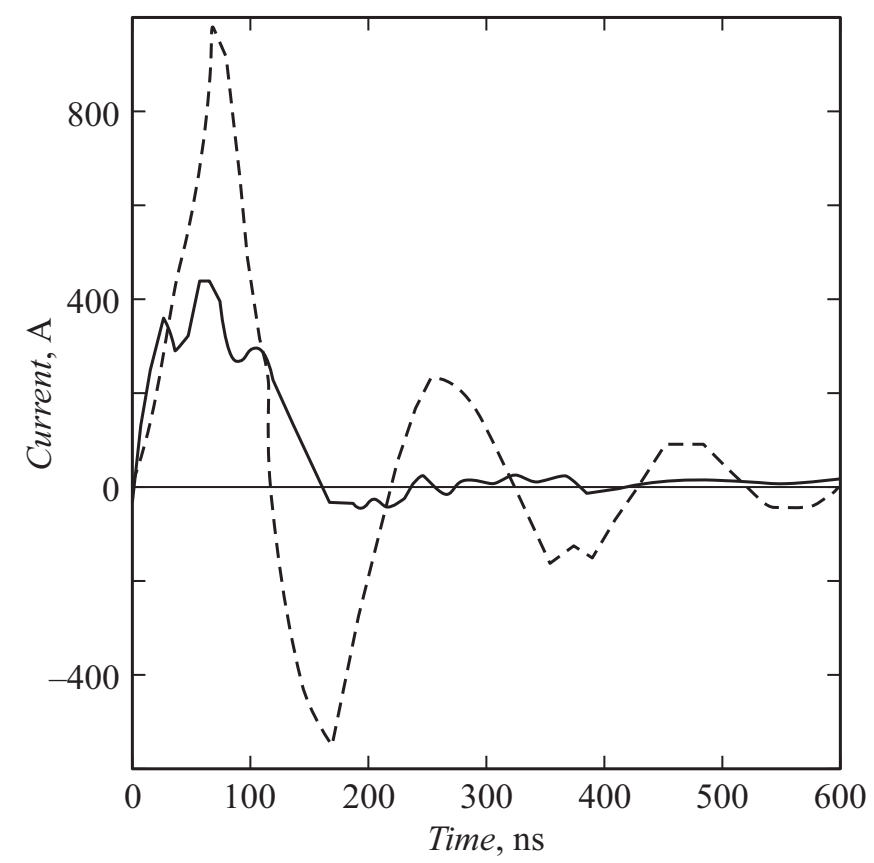

Рис. 3. Осциллограммы тока в различные моменты времени: движение ударной волны по зоне разряда (штриховая кривая) и в потоке за ударной волной через $90 \mu$ s после ухода ударной волны от препятствия (сплошная кривая). 
вдоль уступа с подветренной стороны - в зону вихря, возникающего в результате дифракции ударной волны на обратном уступе (рис. 2, $b$, первый режим). Этот канал, визуализируемый на некотором удалении от препятствия, представляет собой короткоживущее плазменное образование, локализованное в зоне отрыва за уступом при сверхзвуковом обтекании препятствия (в данном режиме перед уступом устанавливается головная ударная волна). При снижении скорости потока до трансзвуковых значений на временно́м интервале $t=700-1200 \mu \mathrm{s}$ реализуется второй режим с двумя линейными каналами пробоя разряда одновременно и в подветренной, и в наветренной областях у препятствия (рис. $2, c$ ). Головная ударная волна перед уступом ослабевает и пропадает. Канал в подветренной области отстоит от препятствия, как и в первом режиме, но интенсивность свечения становится значительно меньше. При дальнейшем снижении скорости потока в канале ударной трубы (после $1200-1300 \mu \mathrm{s})$ головная ударная волна перед уступом пропадает окончательно, зона минимальной плотности перераспределяется в дозвуковую отрывную область перед препятствием. Реализуется третий режим локализации энергии разряда - в канал на кромке уступа с наветренной стороны (рис. $2, d$ ). Позже - при турбулизации течения в канале и инициировании пробоев вдоль пограничного слоя на стекле (после $2.8 \mathrm{~ms}$ ) - эффект пропадает.

Показано, что разным стадиям развития потока (и режимам локализации разряда) отвечают различные осциллограммы тока. На рис. 3 представлены осциллограммы тока, которые соответствуют ионизации потока при прохождении ударной волны по разрядной зоне (рис. 3, штриховая кривая) и после ее ухода из разрядного промежутка (стационарное сверхзвуковое обтекание с локализацией с подветренной стороны препятствия) (рис. 3, сплошная кривая).

Таким образом, плазма импульсного объемного разряда с предыонизацией при инициировании на участке газодинамического канала с уступом самолокализуется в виде короткоживущих сильноточных плазменных каналов в трех конфигурациях в зонах отрыва около уступа. Перераспределение разряда происходит по мере эволюции течения в канале (снижение скорости и турбулизация потока).

\section{Финансирование работы}

Работа выполнена при финансовой поддержке Российского научного фонда (грант 18-19-00672).

\section{Конфликт интересов}

Авторы заявляют, что у них нет конфликта интересов.

\section{Список литературы}

[1] Bayoda K.D., Benard N., Moreau E. // J. Appl. Phys. 2015. V. 118. P. 063301. DOI: $10.1063 / 1.4927844$

[2] Лапушкина Т.А., Ерофеев А.В. // Письма в ЖТФ. 2017. T. 43. B. 5. C. $17-23$. DOI: 10.21883/PJTF.2017.05.44357.16509

[3] Дорощенко И.А., Знаменская И.А., Кузнещов А.Ю., Мурсенкова И.В., Сысоев Н.Н. // ЖТФ. 2018. Т. 88. В. 5. С. 684 691. DOI: $10.21883 / J T F .2018 .05 .45895 .2435$

[4] Ukai T., Russell A., Zare-Behtash H., Kontis K. // Phys. Fluids. 2018. V. 30. P. 116106. DOI: $10.1063 / 1.5054263$

[5] Zheng J.G., Cui Y.D., Li J., Khoo B.C. // Phys. Fluids. 2018. V. 30. P. 040907. DOI: $10.1063 / 1.5012054$

[6] Ruisi R., Zare-Behtash H., Kontis K., Erfani R. // Acta Astronaut. 2016. V. 126. P. 354-363. DOI: $10.1016 /$ j.actaastro.2016.05.016

[7] Leonov S.B., Adamovich I.V., Soloviev V.R. // Plasma Sources Sci. Technol. 2016. V. 25. P. 063001.

[8] Знаменская И.А., Иванов И.Э., Крюков И.А., Кулизаде Т.А. // ЖЭТФ. 2002. Т. 122. В. 6. С. 1198-1206.

[9] Знаменская И.А., Сысоев Н.Н., Jin J. // Письма в ЖТФ. 2013. T. 39. B. 9. C. $28-33$.

[10] Баженова Т.В., Гвоздева Л.Г. Нестационарные взаимодействия ударных волн. М.: Наука, 1977. 274 с.

[11] Краснов Н.Ф., Кошевой В.Н., Калугин В.Т. Аэродинамика отрывных течений. М.: Высш. шк., 1988. 351 с.

[12] Skews B.W. // J. Fluid Mech. 1967. V. 29. P. 705-719. DOI: https://doi.org/10.1017/S0022112067001132

[13] Znamenskaya I.A., Kuli-zade T.A., Kulikov V.N., Perminov S.P. // J. Flow Visual. Image Proc. 2011. V. 18. P. 214-224. DOI: 10.1615/JFlowVisImageProc.2011002204 